\title{
O NEGRO COMO PERSONAGEM NA LITERATURA INFANTIL, NA OBRA DE MARIA RITA PY
}

HE NEGRO AS CHARACTER IN LITERATURE CHILDREN ON THE WORK OF MARIA RITA PY

\author{
Jucineide Vaz dos Santos
}

\begin{abstract}
RESUMO
Procurou-se ao analisar nas obras da Coleção História da Vó Preta, da autora santa-mariense Maria Rita Py, a representação do negro, demonstrando como as questões que o envolvem na sociedade, seus anseios, mágoas, vividas desde o século passado, estão presentes na literatura infantil contemporânea. A literatura tem evidenciado uma preocupação cada vez maior em apresentar uma identidade cultural que expresse as relações de inclusão social. A realidade brasileira mostra que o negro, após a libertação dos escravos, e mais recentemente com o crescimento do movimento negro assumiu uma nova visão, criando um novo discurso nessa literatura, quando passa a ser personagem da transformação da consciência negra. Neste contexto que se insere a literatura negra de Maria Rita, dedicadas ao público infantil, destaca-se a preocupação em buscar soluções para resolver os problemas dos seus personagens tais como: frustração, rejeição, desejo de ser branco, dúvidas e os anseios de crianças negras na sociedade, mas que afetam a auto-estima e a sua identidade.
\end{abstract}

Palavras-chave: africanidade, auto-estima, resgate da história oral das crianças negras, herança cultural, multiculturalismo, identidade cultural, cidadania.

\begin{abstract}
Tried to when analyzing the works of Coleção História da Vó Preta, of the Santa Mariense author Maria Rita Py, the representation of black people, showing how the issues surrounding it in society, his yearnings, sorrows, lived since last century, are present in contemporary children's literature. The literature has shown an increasing concern in presenting a cultural identity that expresses the relationship of social inclusion. The Brazilian reality shows that the black, after the liberations of slaves, and most recently with the growth of the black movement, assumed a new vision, creating a new discourse in this literature, when passing to be personage of the transformation of black spirit (sense). It is in this context that the black literature of Maria Rita Py inserts, dedicated to child audience, search for solutions to solve the problems of this personage such as frustration, rejection, desire to be white, doubts and anxieties of children black in society, affect self-esteem and identity
\end{abstract}

Key-words: African, Self-esteem, Cultural heritage, Multiculturalism, Cultural Identity, Citizenship. 


\section{INTRODUÇÃO}

Este trabalho tem como tema o estudo da representação do negro na obras da Coleção História da Vó Preta, da autora santa-mariense Maria Rita Py com o objetivo de demonstrar como as questões que envolvem o negro na sociedade, seus anseios e mágoas, vívidas desde o século passado, estão presentes na literatura infantil contemporânea.

A autora em estudo com obras dedicadas ao público infantil, destaca-se por sua preocupação em buscar soluções para resolver os problemas dos seus personagens tais como: frustração, rejeição, desejo de ser branco, as dúvidas e os anseios de crianças negras na sociedade; o reflexo de séculos de repressão, que ocorriam a princípio abertamente, e que hoje ainda aparecem de forma velada, mas que afetam a auto-estima e a identidade da criança negra.

A literatura infantil contemporânea tem evidenciado uma preocupação cada vez maior em apresentar uma identidade cultural que expresse as relações de inclusão social. É neste novo contexto que a literatura negra se insere, incluindo um novo discurso na literatura brasileira.

Ao referir-se á literatura negra primeiramente tem de se falar da participação do negro na História do Brasil, sua contribuição, seu sofrimento, a escravidão. Isto é falar dessa identidade por muitos esquecidos, até pelos próprios negros, que têm dificuldade de entender-se, como parte integrante da construção do nosso país. Sem esquecer suas origens e de como veio parar aqui, mas com nova identidade, o negro reescreve sua história.

Como destaca Nelly Novaes Coelho, "para um livro ser considerado renovador ou atualizado, literariamente, não basta que utilize em sua efabulação temas ou problemas vitais desta nossa sociedade em transformação. É preciso mais: que tal contexto "ideológico" (quando existir) se transfigure em arte". Por isso entende-se necessário investigar de que forma Maria Rita constrói suas narrativas e seus personagens, transformando conceitos e preconceitos em arte literária, em qualidade de leitura para o público infantil.

\section{MATERIAIS E MÉTODOS}

Para desenvolver o objetivo proposto, buscou-se, analisar a Literatura Negra, com uma abordagem em conceitos e preconceitos a fim de apresentar aspectos relevantes sobre o tema. Como embasamento teórico, optou-se pelo enfoque proposto por Zilá Bernd, em Introdução à Literatura Negra (1988), onde a autora apresenta conceitos sobre raça e literatura negra, abordando tópicos como racismo, marginalização, exclusão, preconceito.

Tal pesquisa foi realizada com base em metodologias qualitativas, fazendo-se análise de textos e discurso, onde busquei localizar os conceitos e ideias chave nas seguintes obras de Maria Rita Py: livro Os problemas de Júnior (2003), Dia dos Negros (2005), A Turma da Layla (2005), O Sonho de Jamila (2005) e Zeca - Um Herói Negro (2008). 


\section{SANTOS, vol.(4), $\mathrm{n}^{\circ}$ 4, p. 915-921, 2011. Monografias Ambientais (e-ISSN: 2236-1308)}

REMOA

\section{RESULTADOS E DISCUSSÃO}

A maneira como os personagens enfrentam as situações nas obras da autora representam um desafio na sociedade atual, a qual mascara o racismo, com atitudes "politicamente corretas", como a inclusão de personagens negros em cargos de chefia nas telenovelas, na literatura, sem que isso signifique, efetivamente, uma real aceitação. Maria Rita tematiza essas questões, ao construir personagens negros que refletem sobre as questões relacionadas ao preconceito.

Analisando as obras, observa-se que a escritora enfatiza o preconceito contra o negro, representado em seus personagens infantis ao mesmo tempo em que procura reconstruir a autoestima, através da valorização da história da África e valores estéticos próprios da negritude.

É interessante notar a possibilidade de a Coleção da autora Maria Rita Py proporcionar o retorno do papel do professor como "contador de histórias", reportando-nos aos longínquos tempos onde as crianças se reuniam em torno da vovó preta e de sua figura carismática e acolhedora. Isto por si só já é um fator de integração aluno-professor, quer por incutir na mente infantil a figura já folclórica da "vovó das historinhas", quer pelo resgate da tradição oral, ou pela facilitação em se ter a atenção das crianças centralizada na figura do professor.

O livro Os problemas de Júnior, editado no ano de 2003, foi a primeira obra escrita pela autora, fruto de sua experiência pessoal. A partir desta obra, a escritora se sente influenciada a escrever a Coleção Histórias da Vó Preta. A narrativa conta que Junior voltou da escola muito triste, pois o colega tinha o chamado de "negro". Ele não conseguia entender porque seu melhor amigo havia Ihe agredido deste jeito. Eles eram tão parecidos e tão amigos; tinham a mesma idade, brincavam juntos, estudavam na mesma escola. A vovó Ada, depois de ter escutado a conversa de Junior com sua mãe, contou ao neto que os afro-descendentes são herdeiros de Zumbi, um herói negro brasileiro e que todo cidadão negro que nasce no Brasil é chamado de afro-brasileiro. A avó conversou bastante com o neto e aproveitou para dizer que as pessoas são diferentes, pois pertencem a etnias diferentes. Existem brancos, negros, índios e amarelos. Mas quanto à raça, todos são iguais, porque pertencem a raça humana.

A primeira obra da Coleção, Dia dos Negros, apresenta como enredo a história vivida em uma sala de aula. A professora, Maria Gessy, chega na sala de aula e se depara com uma frase escrita no quadro alusiva à data de Treze de Maio. Descobre que um aluno de nome William quisera homenagear um outro colega.

$\mathrm{Na}$ obra, a representação do negro como personagem da literatura infantil é abordada pela situação vivida por Bwana, que é motivo de chacota, brincadeiras de mau gosto por seu colega de classe William, que escreve no quadro a frase "DIA DOS NEGROS! PARABÉNS BWANA!" (p.7). Questionado, Willian se justifica, dizendo: "Eu quero lembrar que hoje é 13 de maio e meu pai falou que é o dia dos negros. Apenas quis fazer uma brincadeira com o Bwana, sem querer ofender, pois afinal ele é um colega tão brilhante e eu gosto muito dele. Segundo minha família, ele é um negro de 'alma branca'."

Bwana pede a palavra e agradece a homenagem, mas aponta os erros históricos cometidos, dizendo que o trabalho nas charqueadas era péssimo, e os escravos viviam pouco, não se podendo dizer que tinham sido bem tratados. Depois falou que a data de treze de maio, tinha sido ruim para o povo negro, pois ele tinha sido libertado e ponto final, não Ihe sendo dada nenhuma forma de amparo, não foram alfabetizados, e nem ganharam um pedaço de terra em que pudessem trabalhar, num total descaso por parte do governo.

Ainda sobre o treze de maio, Bwana disse não ser o dia de homenagem aos negros. $O$ dia para homenagem era sim o dia da morte do grande líder Zumbi dos Palmares, no dia 20 de Novembro, 


\section{SANTOS, vol.(4), $\mathrm{n}^{\circ}$ 4, p. 915-921, 2011. Monografias Ambientais (e-ISSN: 2236-1308)}

REMOA

falando sobre a luta dos quilombolas para manterem-se livres do cativeiro e dos ataques por parte de tropas do governo.

Esta discussão desencadeou uma pesquisa, incentivada pela professora, que envolveu todos os alunos, que percorreram as ruas e estabelecimentos, além da Internet, retratando a situação do povo negro na mídia atual, além de um estudo histórico sobre os quilombos, resultando até numa maquete de Palmares. Houve inclusive espaço na imprensa da cidade para a pesquisa dos alunos de Maria Gessy, e William, que começara as discussões, foi o que mais se entusiasmou e aprendeu sobre a cultura negra.

Nesta obra, graças às brincadeiras pejorativas de Willian, a turma toda, através de um trabalho escolhido pelos colegas com títulos diferentes, mas com a mesma temática, ou seja, referente "aos negros" que todos aprenderam a conhecer a verdadeira história de Zumbi dos Palmares, Dia 13 de maio, Dia 20 de novembro, Abolição da escravatura, racismo, preconceito, personagens etc. Com este trabalho pesquisado pelos alunos com ajuda de seus pais, comunidade, as crianças chegaram a conclusão de que os negros não estão nas colunas sociais, apesar de alguns merecerem, estão na coluna policial, sendo bem descritos pela imprensa, na televisão, apenas com papel secundário, no dia a dia sendo ainda discriminados.

Na obra A Turma de Layla, a personagem negra Layla, com seus seis anos, sofre discriminação racial por parte de sua colega de classe, que se nega a brincar com a mesma, a pegar em sua mão na hora da aula de Educação Física. Layla é uma menininha negra muito sensível, e com seis aos, já adora ler poesia, além de desenhar, ilustrando trechos que ela mais gosta, o que demonstra sua personalidade gentil e delicada.

A narrativa procura evidenciar que, desde pequenas, as crianças negras sofrem preconceito, por crianças brancas nas escolas. Estas trazem de casa como herança passada pelos seus pais, avós familiares em geral. Um simples aperto de mãos, um toque de peles, um carinho, um afeto. Para algumas pessoas ainda isto é impossível, pois não admitem ainda em nossos dias a igualdade de sentimentos, de direitos, oportunidades.

Já em $\mathrm{O}$ sonho de Jamila, a personagem pricipal é uma adolescente como qualquer outra de sua idade, com seus sonhos e aspirações. Numa ocasião, a menina desfilou por sua turma, concorrendo á Rainha da Escola. Apesar de ser reconhecidamente muito bonita, Jamila ficou apenas como primeira princesa.

Tendo ela e os colegas estranhado o fato, foram até a comissão julgadora para conversar sobre o fato, e uma das juradas, já rainha de outro concurso, de cor branca, disse-lhe que não seria nunca rainha de coisa alguma, pois descendia de escravos e macacos. Jamila chegou em casa neste dia, muito triste, chorando, e sua mãe querendo saber do ocorrido, ouviu a história, juntamente com toda a família - irmãos e avós.

No decorrer da conversa, cada um dos familiares contou uma situação de discriminação pela qual passara. Ao final, ficou decidido que eles iriam à delegacia registrar a ocorrência, e após, falariam com a direção do colégio, e com a moça que discriminara Jamila. Esta comparece acompanhada de um advogado, e diz que não tinha sido com intenção de ofender que dissera aquelas palavras, irritando o irmão de Jamila, que a estava acompanhado junto com a mãe.

O advogado, valendo-se disto, tenta distorcer os fatos, colocando a moça branca na situação de vítima. Acaba ameaçando o irmão de Jamila com um processo, pois estava "caluniando a moça"'”. Propõe a mãe de Jamila, dona Núbia, que retirasse a queixa e assim ele não abriria o processo contra o irmão de Jamila. Dona Núbia, após pensar muito, decide que os seus direitos de cidadã não podem the ser negados deste jeito e registra uma ocorrência de ameaça contra o advogado e a moça que ofendera Jamila. 


\section{SANTOS, vol.(4), $\mathrm{n}^{\circ}$ 4, p. 915-921, 2011. Monografias Ambientais (e-ISSN: 2236-1308)}

REMOA

Em O sonho de Jamila, o enfoque da auto-estima centraliza-se na personagem Jamila, a qual concorre a Rainha da escola por ser muito bonita, inteligente graciosa, acaba perdendo para uma menina branca, apenas por fugir do convencional: "Foi quando uma moça, membro da comissão, disse-me que eu era muito lindinha, mas que jamais chegaria ao título, por ser negra e descender de macaco" (p.9).

A auto-estima da personagem evidencia-se ainda mais pelo fato de seus colegas de aula também acharem-na bela, e isto ser senso comum na classe. A busca pelos direitos por ter sido ofendida, apoiada por sua família, revela a valorização da cidadania da pessoa negra, a qual deve fazer uso das leis criadas para protegê-lo, sem temer ameaças de qualquer espécie, alem de tentativas de distorcer a realidade dos fatos apenas por trata-se de pessoas humildes.

As personagens Layla e Jamila vivenciam situações comuns nos dias de hoje, tanto nas salas de aula, quanto no convívio diário com outras pessoas, e Maria Rita apresenta o desenrolar dos fatos e a busca das soluções para o preconceito sofrido pelos personagens, meninas negras, presas a um conceito de beleza-padrão imposta pela sociedade e pela mídia.

A Turma da Layla, O Sonho de Jamila, Dia dos Negros são obras nas quais as questões temáticas do negro, como racismo, preconceito, discriminação, Declaração Universal dos Direitos Humanos, Constituição Federal de 1988, Estatuto da Criança e do Adolescente, Lei Paim, ocorrência policial, entre outras, são colocadas em evidência. Sendo direcionadas ao público infantil, apresentam um discurso pouco atrativo, enquanto textos literários, visto que têm como principal objetivo a conscientização sobre as questões do negro no Brasil.

No último livro da Coleção, Zeca, um herói negro, editado no ano de 2008, percebe-se um maior cuidado com a elaboração literária da narrativa. A obra apresenta textos mais curtos em suas páginas, com uma linguagem comum ao público infantil, mais simples, intercalados com ilustrações coloridas e significativas, não descuidando da representação do negro como personagem da principal da narrativa.

O menino Zeca, de cinco anos, leva uma vida comum, como tantos outros garotos da periferia onde mora. Seus pais trabalham durante todo o dia, e nestas horas, ele fica numa creche, onde recebe ensino e alimentação. As dificuldades dos moradores da vila onde vive Zeca são retratadas através de seus pais, os quais, juntamente com os demais moradores, enfrentam os problemas de um dia a dia cheio de carências, com muita força de vontade.

Mas Zeca é um menino que gosta de sonhar, embora seja como qualquer outra criança de sua idade. Após um sonho, em que se viu como um super-herói, Zeca idealiza este herói, no qual se transforma em um cidadão exemplar da vila onde vive; um herói de seu mundo conhecido aos cinco anos de idade. Vive varias aventuras estelares, em naves, mas ao mesmo tempo em que voa com sua roupa de super-herói, ele visualiza a poluição, as fábricas e aciona os bombeiros para dar fim a um incêndio iniciado por fumantes irresponsáveis. Com os poderes de sua imaginação de menino, ele vai até o prédio da prefeitura, falar com o prefeito, para criar uma campanha alertando contra incêndios.

Zeca pede que a mãe lhe faça um roupa igual a de seu sonho, mas, até esta ficar pronta, contentase em ir para a escola com uma roupa de Super-Homem que já tinha.

Em Zeca, um herói negro, Maria Rita enfoca a auto-estima do menino negro, através de seus sonhos, nos quais o personagem acredita que é preciso ter superpoder para ser um cidadão correto, revelando-se assim um menino sonhador como qualquer outra criança de sua idade, independente de sua cor ou lugar onde mora: "Quando dorme, Zeca sonha que cresce e se tornou um Super-Herói Negro, o Zumbi da Vila Esperança" (p.17). Aí então ele voa, viaja em naves espaciais, vai à lua e às estrelas. Quando retorna, Zeca sobrevoa os edifícios da cidade, dá rasantes 


\section{SANTOS, vol.(4), $\mathrm{n}^{\circ}$ 4, p. 915-921, 2011. Monografias Ambientais (e-ISSN: 2236-1308)}

REMOA

sobre os morros, acompanha os bandos de bem-te-vis e sabiás que acordam a comunidade com seu cantarolar. Derrota a turma do mal e pousa mansamente na sua cama.

Para Zilá Bernd (1988: p.21,22), o conceituar literatura negra, à primeira vista, a expressão pode remeter a um conceito etnocêntrico e reacionário, pois é evidente que sensibilidade artística não constitui fator inerente a uma dada etnia.

A literatura negra surgiu como tentativa de preencher vazios criados pela perda gradativa de identidade determinada pelo longo período em que a "cultura negra" foi considerada fora -da -lei. O Brasil constitui-se numa sociedade racista, onde a dominação é sustentada por uma sociedade ainda conservadora. A mídia tem grande poder de conservar e manter o racismo na sociedade, fortalecendo os elos existentes que a sustentam, mostrando a superioridade branca e a discriminação racial contra o negro. Nas leituras escritas, encontramos o personagem negro como um ser inferior, maldoso, sofredor, escravo fiel, negro revoltado, nobre, bandido, contraventor. No cinema raras vezes o negro é personagem principal referindo-se a criança são sempre os pivetes que mais tarde são representados pelos malandros, crioulos doidos, servindo como ironia, piadas, imagens pejorativas

Segundo Carneiro (2005) a colonização portuguesa carregou consigo o mito ibérico da pureza de sangue, trazidos pelos colonizadores para o Brasil e o conceito da Europa em relação à África, o mito da superioridade, No Brasil após abolição da escravatura não foi criada uma política de inclusão para os negros recém libertos, para que os mesmos tivessem direitos garantidos em relação ao branco e o negro até os dias de hoje sofre a desigualdade social na sociedade mesmo sendo livre e apesar do branqueamento.

O Brasil apesar de ser o segundo país com maior população negra do mundo, em contrapartida, não tem uma política de igualdade para todos, não incluiu o negro como cidadão, abstraindo-se durante muito tempo das responsabilidades, preferindo atribuir à desigualdade ao passado escravista, tornando assim mais fácil, explicar o porquê da miséria, injustiça etc.

Avanços vieram com a Lei Afonso Arinos de 1951, que legalmente passa a combater o preconceito racial, á xenofobia, incluindo como contravenção penal, atos de preconceitos "de raça ou de cor". $\mathrm{Na}$ Constituição Federal de 1988, o racismo passa a ser considerado como crime inafiançável (Lei Caó e Lei Paim). A partir do ano 2000 várias cidades brasileiras criaram o serviço SOS racismo, sendo este de grande valia para contornar problemas criados pela falsa democracia racial. Finalmente o governo brasileiro reconheceu oficialmente o racismo no país apenas em 1995, ao instituir políticas de "Ações Afirmativas" para negros (e indígenas), com o Presidente Lula, também criando a Secretaria especial de Promoção de Desigualdade Racial. Outro avanço foi a lei 10639/2003 que tornou obrigatório os estudos sobre a África nas Escolas que em médio prazo poderá contribuir para uma melhor inclusão do negro, em sala de aula e sociedade, por trabalhar as diferenças.

A maneira como os personagens enfrentam as situações nas obras de Maria Rita, representam um desafio na sociedade atual, que mascara o racismo, com atitudes "politicamente corretas", como a inclusão de personagens negros em cargos de chefia nas telenovelas, na literatura, sem que isso signifique, efetivamente, uma real aceitação. Maria Rita aborda essas questões de uma forma inovadora, ao construir personagens que refletem sobre as questões relacionadas ao preconceito que sofrem e como podem ser valorizados em seu ambiente sócio-cultural.

Ao analisar-se a Coleção História da Vó Preta, tendo como perspectiva a questão racial dos personagens, a feminilidade, a discussão sobre o belo, entre as crianças, conclui-se que através delas, a criança negra pode se identificar com os personagens, reconstruindo-se como belo, herói, desmistificando-se os preconceitos que constantemente assolam o seu cotidiano. 
Desta forma a criança negra pode melhorar sua auto-estima, resgatando sua história de vida bem com a de seus antepassados, reconstituindo sua identidade, postando-se como elemento importante no mundo multicultural, presente com tanta força na sociedade.

Ao construir essa trajetória que resgata sua cultura, seu passado histórico, a criança negra reconstrói uma identidade cultural fortalecida, passa a reivindicar seus direitos, construindo-se como cidadão, nesse país em que seus antepassados ajudaram a construir.

\section{REFERENCIAS BIBLIOGRÁFICAS}

BERNDT, Zilá. Introdução à Literatura Negra. SP, Editora Brasiliense, 1988.

COELHO, Nelly Novaes. Panorama histórico da Literatura Infantil, Juvenil. SP, Editora Ática, 1991.

GOUVÊA, Maria Cristina Soares. Imagem do Negro na Literatura Brasileira. SP. Educação e Pesquisa, 2005.

MUNANGA, Kabengele. Superando o Racismo na Escola. Brasília, Editora MEC, 2005.

SILVA, Terezinha Juraci Machado da. Estereótipos sobre a Inferioridade do Negro na Literatura. Trabalho Acadêmico, 1988.

TEUN, A. Van Dijk. Racismo e discurso na América Latina. SP, Editora Contexto, 2008. 